\title{
Marcadores anatômicos do pecíolo e a tolerância à seca de ponteiros e ao déficit hídrico em eucalipto
}

\author{
Samyra Alves CONDÉ ${ }^{*}$, Edgard Augusto de Toledo PICOLI ${ }^{1}$, Thais Roseli CORRÊA ${ }^{2}$, \\ Rodrigo Dal Sasso LOURENÇO ${ }^{3}$
}

\author{
${ }^{1}$ Programa de Pós-Graduação em Fitotecnia (Produção Vegetal), Universidade Federal de Viçosa, Viçosa, MG, Brasil. \\ (Orcid: *; 0000-0002-6275-2684) \\ ${ }^{2}$ Centro de Ciências Agrárias, Universidade Estadual do Maranhão, São Luís, MA, Brasil. (Orcid: 0000-0003-3131-4996) \\ ${ }^{3}$ Programa de Pós-Graduação em Engenharia Agrícola, Universidade Federal de Viçosa, Viçosa, MG, Brasil. \\ (Orcid: 0000-0002-9316-8253) \\ *E-mail: samyraconde@yahoo.com.br (Orcid: 0000-0002-8091-5483)
}

Recebido em 31/07/2019; Aceito em 28/08/2020; Publicado em 11/09/2020.

\begin{abstract}
RESUMO: A seca de ponteiros em Eucalipto é um distúrbio fisiológico, onde o estresse hídrico vem sendo associado como um dos fatores intensificadores de sua ocorrência. A seleção precoce de genótipos de eucalipto tolerantes a essas condições, podem fornecer informações relevantes quanto a esse distúrbio. Objetivou-se avaliar possíveis marcadores anatômicos, associados a tolerância ao déficit hídrico e à seca de ponteiros. Genótipos comerciais com diferentes graus de suscetibilidade a seca de ponteiros foram submetidos a diferentes níveis de estresse hídrico em condições de casa de vegetação. A duração do experimento foi de 75 dias. Amostras de pecíolos foram coletadas e avaliadas as características das áreas anatômicas de: seção transversal, tecido vascular, xilema, floema e do córtex. Os dados foram submetidos à análise da variância (ANOVA) e para comparação de médias foi adotado o teste Tukey $(\mathrm{p}<0,05)$. Os resultados mostraram que há a tendência de redução de todas as variáveis avaliadas com o aumento do déficit hídrico. Entretanto, o genótipo tolerante em condições de maior restrição hídrica apresenta maior área de seção transversal e de tecidos condutores em comparação ao suscetível. A maior proporção destes tecidos sugere que o clone tolerante apresenta condição mais favorável ao transporte de água, fotoassimilados e nutrientes.
\end{abstract}

Palavras-chave: melhoramento florestal; silvicultura; seleção genômica.

\section{Anatomical markers of petiole and tolerance to die-back and water stress in eucalyptus}

\begin{abstract}
Die-Back in Eucalyptus is a physiological disorder where the water stress has been associated as an intensifier of this occurrence. The early selection of tolerant Eucalyptus genotypes to water stress can provide relevant information to this disorder. The research aimed to evaluate possible anatomical markers associated with tolerance to water stress and Die-Back. Commercial genotypes with different levels of susceptibility to this disorder were submitted to different levels of water stress in a greenhouse condition. The experiment lasted 75 days. Petioles samples were collected and anatomical characteristics were evaluated: crosssectional area, area of vascular tissue, xylem area, phloem area and cortical area. The data were submitted to analysis of variance (ANOVA) and for the comparison of means was adopted Tukey test $(\mathrm{p}<0.05)$. The results show us that there is a tendency to reduce all variables with increasing water deficit. However, the tolerant genotype in higher water stress conditions has greater cross-sectional area and conducting tissues compared to susceptible genotype. The major proportion of these tissues suggests that the tolerant clone presents more favorable condition for transport of water, nutrients and assimilates.
\end{abstract}

Keywords: forest improvement; forestry; genomic selection.

\section{INTRODUÇÃO}

A madeira de Eucalipto é utilizada para o abastecimento da maior parte da indústria de base florestal brasileira, sendo o gênero florestal mais implantado e estudado no país (IBÁ, 2017). Em razão da sua boa adaptação às diferentes condições de solo e clima e elevada produtividade. De acordo com o anuário estatístico de 2017 da Industria Brasileira de Árvores-IBÁ, (2017) a área brasileira de plantios florestais, em 2016, atingiu 7,84 milhões de hectares, sendo que os plantios de eucalipto representam $72,3 \%$ desta área.
Dentre as principais espécies utilizadas no país, Eucalyptus grandis e seus híbridos interespecíficos, principalmente com a espécie E. urophylla, continuam sendo as mais importantes, em face de seu uso intensivo e crescente nos segmentos industriais devido a qualidade da madeira (PINTO JÚNIOR; GARLIPP, 2008).

Novas fronteiras agrícolas, como o cerrado, têm sido exploradas com a expansão do cultivo de eucalipto no Brasil. Frequentemente, as plantas se encontram sob condições adversas ao desenvolvimento como solos com fertilidade 
nem sempre favoráveis, aliados a períodos com déficit hídrico e altas temperaturas (CAMBRAIA, 2015). Essas áreas com limitações ao crescimento do eucalipto vêm contribuindo, de maneira decisiva, para o aparecimento de distúrbios que não eram comuns.

Os principais fatores ambientais que podem causar estresse em uma planta são: radiação solar, temperatura e água (SOUZA et al., 2006). Segundo Paiva et al. (2005) o déficit ou o excesso hídrico são os mais limitantes para a sustentabilidade dos sistemas florestais, pois afetam diretamente o metabolismo das plantas, causando grandes perdas produtivas.

Como resposta a deficiência ou o excesso hídrico, as plantas passam por mudanças fundamentais na relação da célula com a água e nos seus processos fisiológicos e anatômicos (CHAVES et al., 2004). O que pode influenciar a sua capacidade de tolerar as condições adversas do meio. Essas condições de estresse de água, também contribuem para ocorrência de distúrbios que podem prejudicar a cultura e a produtividade das plantas de eucalipto, dentre eles, a seca de ponteiros.

A seca de ponteiros é considerada uma enfermidade de etiologia complexa, induzida por fatores abióticos e bióticos (ALFENAS et al., 2009; JURSKIS, 2005). A intensidade dos sintomas, parece estar ligada à idade do eucalipto, uma vez que são expressos até o terceiro e/ou, quarto ano de plantio, particularmente durante os meses mais secos dos anos. Após este período, esse distúrbio tem seus sintomas pouco expressos. Isso acontece, provavelmente, pelo aumento do índice de área foliar quando o plantio se torna mais velho, possibilitando maior demanda transpiratória pelas plantas (MATTIELLO et al., 2009).

A introdução de material genético adaptado às condições de estresse hídrico e aos distúrbios fisiológicos advindos deste estresse é essencial para a manutenção do potencial produtivo do setor florestal, sendo hoje um dos objetivos do melhoramento genético florestal. No entanto, o melhoramento genético do eucalipto é limitado pelos longos períodos e custos de avaliação necessários para obtenção das cultivares desejáveis (BELTRAME et al., 2012). Cada ciclo de obtenção de progênies, que inclui avaliação e seleção fenotípica, e o cruzamento entre as famílias selecionadas para formar uma nova população, requer aproximadamente 10 anos (PEREIRA et al., 1997).

Desta forma, a seleção precoce de genótipos produtivos resistentes ao distúrbio da seca de ponteiros e / ou tolerantes ao déficit hídrico pode contribuir para o incremento na produtividade e para a otimização das áreas de plantio (MORAES et al., 2014). Para que isso seja possível, a identificação de marcadores relacionados a tolerância a este distúrbio reduziria o tempo de seleção de genótipos para formação de plantios comerciais.

Esta seleção pode ser realizada com base em marcadores genéticos, definidos como características que podem diferenciar dois ou mais genótipos. Estas características podem ser morfológicas, fisiológicas, moleculares dentre outras. Alguns trabalhos apontaram que características do pecíolo e folha como poderiam indicar diferenças na capacidade de escape ao déficit hídrico em diferentes espécies vegetais (KULKARNI et al., 2007).

O objetivo desse trabalho foi avaliar possíveis marcadores anatômicos associados a anatomia do pecíolo e a tolerância à seca de ponteiros e déficit hídrico em eucalipto a partir da avaliação de genótipos divergentes, cultivados sob a simulação de estresse hídrico em condições de casa de vegetação.

\section{MATERIAL E MÉTODOS}

Para a realização do experimento foram utilizados três genótipos comerciais (Tabela 1), disponibilizados pela empresa Suzano Papel e Celulose. Informações sobre o grau de tolerância à seca de ponteiros de cada genótipo foram disponibilizadas pela empresa, tais informações foram levantadas de acordo com o histórico destes clones nas áreas de produção mais propensas à ocorrência desse distúrbio.

Tabela 1. Genótipos comerciais de eucalipto e classificação dos mesmos quanto a tolerância e suscetibilidade a seca de ponteiros. Table 1. Commercial eucalyptus genotypes and their classification for tolerance and Die-back susceptibility.

\begin{tabular}{ccc}
\hline Genótipo & Background Genético & $\begin{array}{c}\text { Classificação dos } \\
\text { genótipos quanto a } \\
\text { seca de ponteiros }\end{array}$ \\
\hline Suz 1 & E. grandis & Suscetível \\
Suz 2 & E. grandis $\times$ E. urophylla & $\begin{array}{c}\text { Médio Tolerante } \\
\text { Tolerante }\end{array}$ \\
Suz 3 & E. grandis $\times$ E. urophylla & \\
\hline
\end{tabular}

Mudas com aproximadamente 120 dias foram transplantadas para sacos plásticos de volume de 2 litros contendo substrato de casca de arroz carbonizada e adubo. As mesmas foram aclimatadas em casa de vegetação em temperatura média de $25^{\circ} \mathrm{C}$, com iluminação natural e irrigação diária.

O experimento foi realizado nas instalações da empresa Clonar, Zona Rural de Cajuri - MG, com os três genótipos comerciais e quatro tratamentos conforme designados na Tabela 2:

Tabela 2. Descrições dos tratamentos de simulação de déficit hídrico aplicados para seleção precoce quanto a seca de ponteiros em três genótipos comerciais de eucalipto.

Table 2. Descriptions of water stress simulation treatments applied for early selection for Die-back in three commercial eucalyptus genotypes.

Tratamento

1- Controle Plantas mantidas em casa de vegetação, em recipientes plásticos de $2 \mathrm{~L}$ com substrato casca de arroz carbonizada, adubação, temperatura média de $25^{\circ} \mathrm{C}$, iluminado com luz natural e irrigação diária.

2 - Bandeja Procedimento padrão do viveiro (controle) e manutenção de lâmina d'água $(3 \mathrm{~cm})$ constante em bandejas onde foram mantidos os vasos contendo as mudas.

3 - $100 \mathrm{~g} \mathrm{~L}^{-1} \quad$ Procedimento padrão do viveiro (controle) e PEG simulação de estresse hídrico com a aplicação de $100 \mathrm{~mL}$ de solução de polietileno glicol 6000 (PEG) na concentração de $100 \mathrm{~g} \mathrm{~L}^{-1}$ por vaso, a cada dois dias durante o período do experimento.

4 - $300 \mathrm{~g} \mathrm{~L}^{-1} \quad$ Procedimento padrão do viveiro (controle) e PEG simulação de estresse hídrico com a aplicação de $100 \mathrm{~mL}$ de solução de polietileno glicol 6000 (PEG) na concentração de $300 \mathrm{~g} \mathrm{~L}^{-1}$ por vaso, a cada dois dias durante o período do experimento.

O experimento foi montado em um delineamento em blocos casualizados, em um esquema fatorial $3 \times 4$, onde cada 
bloco apresentava a combinação dos quatro tratamentos e dos três genótipos. Todas as combinações de genótipo e tratamento foram constituídas por parcelas de três plantas e distribuídas em seis blocos. O experimento teve duração de aproximadamente 75 dias, quando foram coletados os dados da anatomia do pecíolo.

Para as análises anatômicas, foram coletadas quatro plantas por tratamento, e utilizados pecíolos de folhas totalmente expandidas. As amostras do pecíolo foram fixadas em FAA50 (formaldeído, ácido acético e álcool etílico 50\%, na proporção de 5:5:90, v:v:v), por 48 horas e estocadas em etanol 70\% (Johansen, 1940). Posteriormente a parte mediana (50\% do seu comprimento) do pecíolo foi isolada e desidratada na sequência de etanol $85 \%$ e $95 \%$, sendo mantida por 2 horas em cada. Em seguida, as amostras foram submetidas à mistura de etanos $95 \%$ e resina pura (Historesin Leica, preparada conforme instrução do fabricante), na proporção de $1 \mathrm{v}: 1 \mathrm{v}$, por 96 horas.

A infiltração foi feita com resina pura, em um dessecador submetido a vácuo, e em intervalos de 12 horas cada em um período de 7 dias. A resina pura foi misturada ao endurecedor, conforme as instruções do fabricante, e as amostras emblocadas em moldes plásticos. Na sequência esses moldes ficaram 72 horas em estufa a $35^{\circ} \mathrm{C}$ e finalmente preparados em blocos de madeiras. Secções transversais com $5 \mu \mathrm{m}$ de espessura foram obtidas em micrótomo rotativo automático (RM2155, Leica Microsystems Inc., EUA), com navalhas de vidro.

Os cortes obtidos foram destinados a um recipiente contendo água quente, aderidos em lâminas histológicas e posteriormente coradas com azul de toluidina $0,05 \%, \mathrm{pH} 6,5$ e montadas com resina sintética (Permount, Fisher Scientific, EUA).

As imagens foram obtidas em câmera fotográfica digital (AxioCam HRc, Zeiss, Alemanha) e microcomputador com programa de captura de imagens

acoplados a um microscópio de luz (AX-70 TRF, Olympus Optical, Japão).

Essas imagens foram analisadas em software para análise de imagens Image pro plus, com a medição de cinco campos por repetição, para cada variável analisada. Dentro de cada campo foram realizadas cinco medições e obtida a média. Foram determinadas a área de seção transversal, área do tecido vascular, área do xilema, área do floema e área do córtex.

As análises estatísticas, foram submetidos à análise da variância (ANOVA), com o auxílio do programa SAS (SAS Institute, 2002). Para a comparação das médias foi adotado o teste de Tukey $(\mathrm{p}<0,05)$.

\section{RESULTADOS}

Ao avaliarmos o comportamento dos diferentes genótipos com tolerância diferencial a seca de ponteiros, em condições de abundância de água (tratamento bandeja e controle) e os tratamentos com restrição de água (100PEG e 300 PEG), foi possível observar que o genótipo Suzano 2 (médio tolerante) apresentou comportamento intermediário em relação a variável área de seção transversal do pecíolo, à medida que se aumentava a restrição de água, essa variável apresentou redução (Figura 1).

Nas mesmas condições, o genótipo Suz 1 (suscetível) apresentou redução da área de seção transversal do pecíolo, sendo esta, maior que os demais genótipos. O genótipo Suz 3 (tolerante), sob a condição de maior restrição de água apresentou redução da área de seção transversal e depois um aumento, tendo um comportamento superior aos demais (Figura 1).

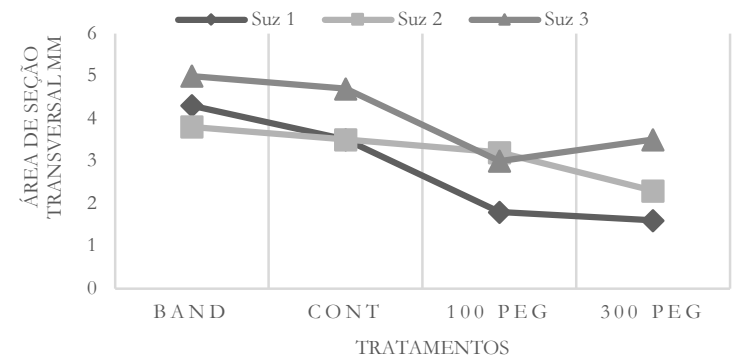

Figura 1. Área de seção transversal de pecíolos de genótipos de eucalipto com tolerância diferencial quanto a seca de ponteiro.

Figure 1. Petiole cross-sectional area of eucalyptus genotypes with differential tolerance to Die-back.

Em relação ao genótipo médio tolerante (Suz 2) este apresentou um comportamento esperado. O genótipo tolerante (Suz 3) apresentou semelhança quanto a essa variável em relação ao genótipo suscetível (Suz 1) nos tratamentos bandeja e controle (Figura 1).

À medida que se aumentava o déficit hídrico o genótipo Suz 3 apresentou redução da área de seção transversal de pecíolo com posterior aumento desta variável no tratamento com maior restrição hídrica.

$\mathrm{Na}$ condição de maior restrição hídrica (300 PEG) o genótipo Suz 3 (tolerante) apresentou curiosamente, aumento da variável área de seção transversal, o que pode ser evidenciado pela Figura 2.

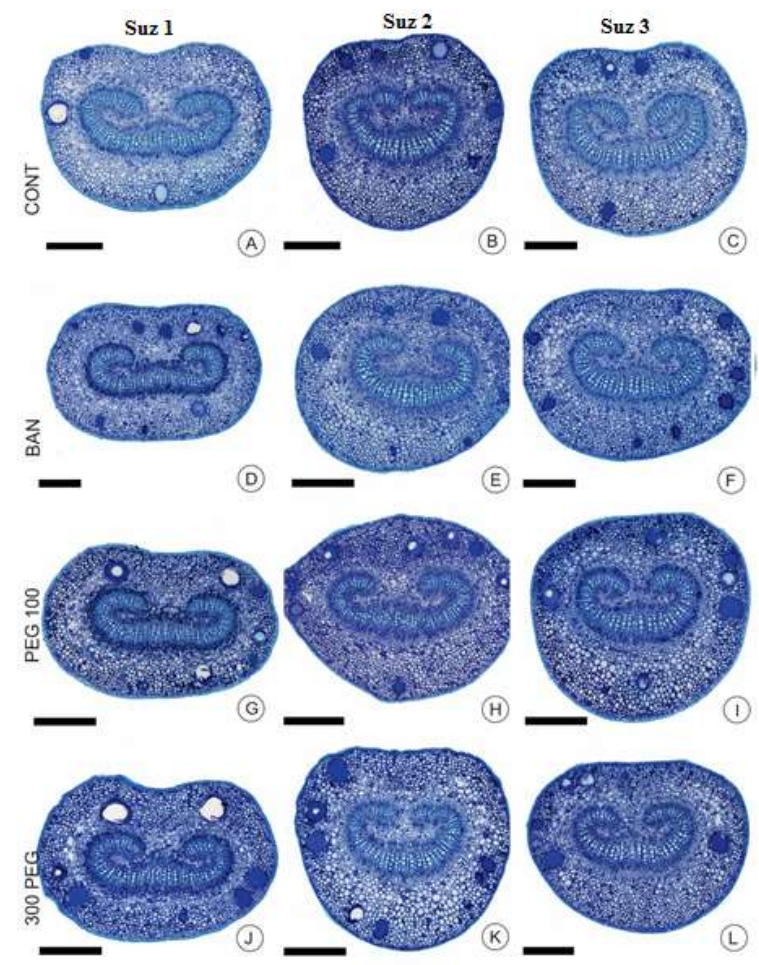

Figura 2. Cortes transversais de pecíolo de genótipos de eucalipto com tolerância diferencial a seca de ponteiros, sob diferentes tratamentos para disponibilidade de água. Barras $=200 \mu \mathrm{m}$. 
Figure 2. Petiole cross sections of eucalyptus genotypes with differential tolerance to Die-back under different treatments for water availability. Bars $=200 \mu \mathrm{m}$.

A área de seção transversal do xilema (Figura 3) reduziu com o aumento do estresse hídrico. Os clones tolerantes (Suz 3) e suscetível (Suz 1) apresentaram redução nos tratamentos 100 PEG e 300 PEG para essa variável mencionada acima. Entretanto, a área de seção transversal do floema apresentou uma redução drástica para o clone Suz 1 (Figura 4). Já o clone Suz 3 apresentou uma queda discreta nas medias entre os tratamentos.

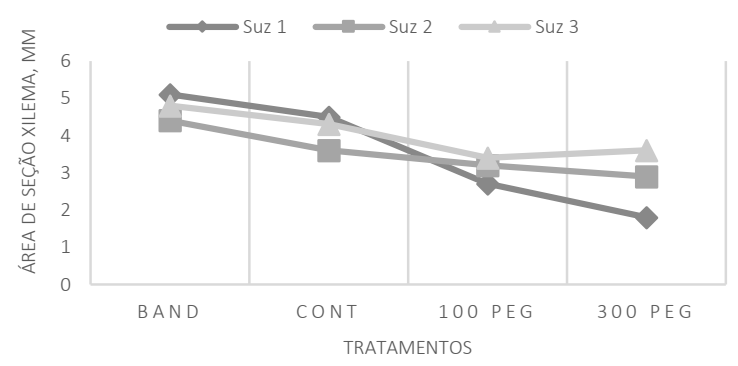

Figura 3. Área de seção do xilema de genótipos de eucalipto com tolerância diferencial a seca de ponteiros.

Figure 3. Petiole's xylem cross-sectional area of eucalyptus genotypes with differential tolerance to Die-back.

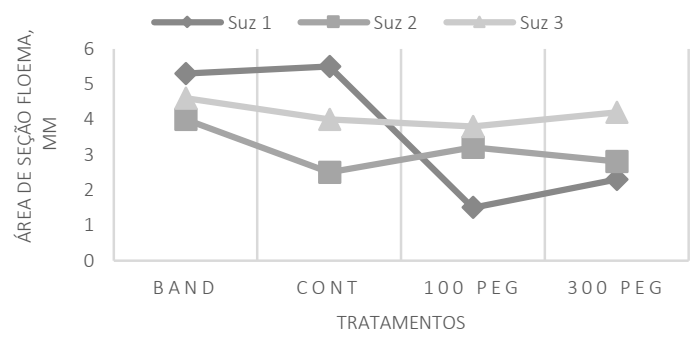

Figura 4. Área de seção do floema de pecíolos de genótipos de eucalipto com tolerância diferencial quanto a seca de ponteiro.

Figure 4. Petiole's phloem cross-sectional area of eucalyptus genotypes with differential tolerance to Die-back.

O genótipo Suz 2 apresentou comportamento intermediário em relação a variável área de tecido vascular, à medida que se aumenta a restrição hídrica, este comportamento é esperado, por ser um material genético classificado como médio tolerante. Enquanto que nas mesmas condições, o genótipo suscetível (Suz 1) apresentou redução da área de tecido vascular, e o genótipo Suz 3 apresentou superioridade em relação aos demais (Figura 5).

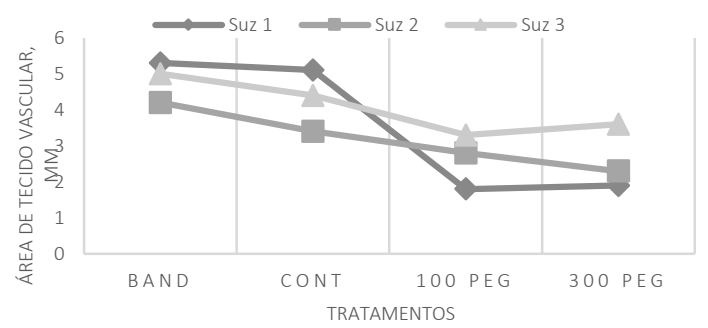

Figura 5. Área de seção de tecido vascular de pecíolos de genótipos de eucalipto com tolerância diferencial quanto a seca de ponteiro.

Figure 5. Petiole's vascular tissue cross-sectional area of eucalyptus genotypes with differential tolerance to Die-back.
A última variável anatômica avaliada foi a área de seção córtex/ epiderme dos clones avaliados (Figura 6). Pode-se notar que o Suz 3 apresentou a maior área de seção córtex/epiderme, em contrapartida, o genótipo Suz 1 apresentou a menor área. E mais uma vez comportamento intermediário apresentado pelo genótipo com média tolerância (Suz 2).

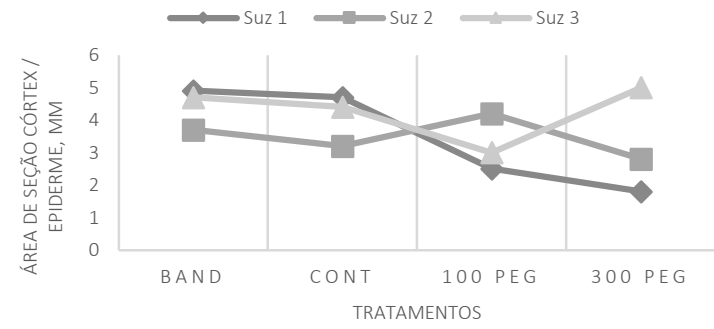

Figura 6. Área de seção córtex/epiderme de pecíolos de genótipos de eucalipto com tolerância diferencial quanto a seca de ponteiro. Figure 6. Petiole's Cortex / epidermis section area of eucalyptus genotypes with differential tolerance to Die-back.

Estes resultados sugerem o que foi encontrado até agora, com maior adaptabilidade do genótipo Suzano 3, que mesmo em condições de restrição hídrica, apresentou menor redução das variáveis anatômicas avaliadas.

\section{DISCUSSÃO}

A deficiência hídrica é um dos fatores abióticos que diminuem o desenvolvimento e o crescimento vegetal e constitui uma das mais relevantes limitações à distribuição e à produtividade dos vegetais, influenciando negativamente nas áreas agrícolas do mundo (BARTELS; SUNKAR, 2005). Devido a isso, as características anatômicas são importantes para estudos relacionados as diversas adaptações nas plantas ocasionadas por condições de estresse, visto que, as modificações anatômicas ocorrem como ajustes as novas condições.

Todas as características anatômicas do pecíolo avaliadas no presente trabalho podem ser usadas como marcadores anatômicos pois são acessíveis e demonstram as modificações ocorridas nas plantas sob diferentes condições hídricas. Esses marcadores, tratamentos e metodologia para seleção precoce de genótipos de eucalipto são promissores e com potencial para contribuir com um programa de melhoramento de eucalipto visando a seca de ponteiros relacionada ao déficit hídrico.

A variável área de seção transversal do pecíolo apresentou modificações nos três genótipos avaliados, ocorrendo redução nessa variável à medida que se restringia a disponibilidade de água nos tratamentos. O clone Suz 3 (tolerante) apresentou uma maior diminuição na área de seção transversal do pecíolo nos tratamentos sob estresse hídrico. Castro et al. (2009) afirma que estresses bióticos e abióticos, podem afetar a espessura de tecidos da epiderme, com intuito de proteção contra injúrias e regulação de trocas gasosos. Neste sentido a aumento da área se seção transversal do pecíolo poderia ser uma adaptação para aumentar a resistência desta estrutura bem como proteção ao déficit hídrico.

O xilema também foi outra variável que ocorreu o decréscimo de sua área à medida que aumentava o estresse shídrico nas plantas. Em relação ao mecanismo de funcionamento da planta, as funções do xilema são: 
transporte de seiva, estoque de substâncias como água, minerais e carboidratos e suporte mecânico (BAAS et al., 2004). O clone Suz 1 (suscetível) foi o que apresentou menor área total de xilema nos tratamentos 100PEG e 300 PEG. Essa redução da área total do xilema é devido a adaptações estruturais condicionadas as diferentes condições ambientais. Sem a água no xilema (traqueídeos e elementos de vasos) podem formar bolhas de ar (embolismo) ou ainda interrupção do fluxo (cavitação) pelo estiramento (quebra) da coluna d’água (LI et al., 2009; VALDEZ, 2014). Devido a esses fatores, diminuição nas estruturas do xilema pode promover um transporte mais seguro quando a planta está condicionada a algum estresse (CASTRO et al., 2005).

O floema é o tecido das plantas vasculares encarregados de transportar os produtos fotoassimilados das folhas até as raízes. Em condições de estresse hídrico, a condução de fotoassimilados pelo floema é afetada, de tal forma que alguns tecidos vegetais apresentam redução de reservas de carbono, podendo, em condições extremas, inclusive, levar a planta à morte (SALA et al., 2010). O clone Suz 3 (tolerante), apresentou uma atenuação muito discreta em relação as medias dos diferentes tratamentos. Essa manutenção da área do floema, pode permitir maior fluxo de carboidratos da parte área para as raízes, bem como a translocação de nutrientes necessários para o desenvolvimento da planta e produção dos frutos (PEREIRA et al., 2008; RIBEIRO et al., 2012).

Outra variável avaliada foi a área de tecido vascular, composta pelo xilema e floema. O clone Suz 1 (suscetível) apresentou um declínio nas medias dessa variável, podendo ser uma caraterística que não permita esse clone tolerar as adversidades do meio. Como o tecido vascular é responsável pelo transporte de água e nutrientes, ele é fundamental para a resistência ao déficit hídrico e ao distúrbio. Já o clone Suz 3 (tolerante) apresentou uma pequena variação entre as medias entre os diferentes tratamentos. Resultados semelhantes quanto ao aumento dos tecidos condutores mesmo em condições de restrição de água, foram observados por Alves e Angyalossy-Alfonso (2000). Esses autores concluíram que os fatores ambientais alteram as dimensões e o arranjo dos elementos vasculares de forma positiva, na tentativa de garantir aumento na segurança do transporte, quando a planta está sujeita a algum tipo de estresse.

A última variável avaliada foi a área do córtex/epiderme. No clone Suz 1, aconteceu uma diferença entre essa variável de acordo com a restrição hídrica, sendo a área do córtex menor nas condições de déficit hídrico. Em contrapartida, no clone Suz 3 ocorreu um aumento dessa variável no maior nível de restrição hídrica. Esse aumento dessa variável está relacionado a maior adaptação das plantas as condições de estresse hídrico. Em algumas espécies, a espessura do córtex varia em decorrência da diminuição do potencial hídrico que, por sua vez, conduz a uma contração das células corticais provocada pela diminuição do volume celular (HUANG; FRY, 1998).

O estresse hídrico foi simulado de forma eficiente de acordo com os resultados encontrados, os tratamentos concederam novas condições para uma seleção precoce efetiva. Com isso, pode-se inferir que todas as características anatômicas avaliadas acima, são sim indicadas como bons marcadores anatômicos para a seleção precoce de coles de eucalipto tolerantes à seca de ponteiro e ao déficit hídrico, complementando o trabalho de Correa et al. (2017) que descreve e comprova marcadores nutricionais e morfológicos relacionados a tolerância ao distúrbio e ao déficit hídrico em estudo.

\section{CONCLUSÕES}

O genótipo tolerante a seca de ponteiros apresenta características anatômicas do pecíolo que são coerentes com a maior tolerância ao déficit hídrico.

As variáveis anatômicas do pecíolo: área de seção transversal, xilema, floema, tecido vascular e área do córtex/epiderme foram identificadas como marcadores anatômicos para a seca de ponteiro e ao déficit hídrico em eucalipto, contribuindo de forma efetiva para seleção precoce de clones tolerantes ao distúrbio e ao déficit hídrico.

\section{AGRADECIMENTOS}

À empresa Suzano Papel e Celulose, pelo apoio financeiro aos projetos desenvolvidos. A Universidade Federal de Viçosa por todo ensinamento e estrutura fornecida. A Coordenação de Aperfeiçoamento de Pessoal de Nível Superior- Brasil (Capes) e ao Conselho Nacional de Desenvolvimento Científico e Tecnológico (CNPq).

\section{REFERÊNCIAS}

ALFENAS, A. C.; ZAUZA, E. A.; MAFIA, R. G.; ASSIS, T. F. Clonagem e Doenças do Eucalipto. Viçosa: Editora UFV, 442p. 2009.

ALVES, E. S.; ANGYALOSSY-ALFONSO, V. Ecological trends in the wood of some Brazilian species 1: growth rings and vessels. IAWA Journal, v. 21, p. 3-30, 2000. DOI: http://dx.doi.org/10.1590/2175-7860200657305

BARTELS, D.; SUNKAR, R. Drought and Salt Tolerance in Plants. Critical Reviews in Plant Sciences, v. 24, p. 2358, 2005. DOI: 10.1080/07352680590910410

BAAS P.; EWERS F.W.; DAVIS S. D.; WHEELER E. A. Evolution of xylem physiology. In: POOLE, I.; HEMSLEYA (Eds.). Evolution of plant physiology. London: Elsevier Academic Press; 2004. p. 273-295. Linnaean Society Symposium Series

BELTRAME, R.; BISOGNIN, D. A.; MATTOS, B. D.; CARGNELUTTI FILHO, A.; HASELEIN, C. R.; GATTO, D. A.; SANTOS, G. A. dos. Desempenho silvicultural e seleção precoce de clones de híbridos de eucalipto. Pesquisa Agropecuária Brasileira, Brasília, v. 47, n. 6, p. 791-796, 2012. DOI: http://dx.doi.org/10.1590/S0100-204X2012000600009

CAMBRAIA, J. Aspectos bioquímicos, celulares e fisiológicos dos estresses nutricionais em plantas. In: NOGUEIRA, R. J. M. C.; ARAÚJO, E. de L.; WILLADINO, L. G.; CAVALCANTE, U. M. T. (Eds.). Estresses ambientais: danos e benefícios em plantas. Recife: UFRPE, Imprensa Universitária, p. 95-105, 2005. CASTRO, E. M.; PEREIRA, F. J.; PAIVA, R. Histologia Vegetal: Estrutura e Função de Órgãos Vegetativos. Lavras: UFLA, 234p. 2009.

CHAVES, J. H.; REIS, G. G. dos; REIS, M. das G. F.; NEVES, J. C. L.; PEZZOPANE, J. E. M.; POLLI, H. Q. Seleção precoce de clones de eucalipto para ambientes com disponibilidade diferenciada de água no solo: relações hídricas de plantas em tubetes. Revista Árvore, 
Viçosa, v. 28, n. 3, p. 333-341, 2004. DOI: 10.1590/S0100-67622004000300003

CORRÊA, T. R.; PICOLI, E. A. D. T.; SOUZA, G. A. D; CONDÉ, S. A.; SILVA, N. M.; LOPES M., K. L. B.; RESENDE, M. D. V. D.; ZAUZA, E. A. V.; ODA, S. Phenotypic markers in early selection for tolerance to dieback in Eucalyptus. Industrial Crops and Products, v. 107, p. 130-138, 2017. DOI https://doi.org/10.1016/j.indcrop.2017.05.032

HUANG, B.; FRY, J. D. Root anatomical, physiological, and morphological responses to drought stress for tall fescue cultivars. Crop Science, Madison, v. 38, p. 1017-1022, 1998.

DOI:

10.2135/cropsci1998.0011183X003800040022x

IBÁ - Indústria Brasileira de Árvores. Anuário Estatístico da Indústria Brasileira de Árvores: ano base 2017. Brasília, DF: IBA, 80p., 2017. Disponível em: $<$ https://iba.org/images/shared/Biblioteca/IBA_Relat orioAnual2017.pdf > .Acesso em: 16 jul 2019.

JOHANSEN, D. A. Plant microtechnique. Mc Graw Hill, New York 1940.

JURSKIS V. Eucalypt decline in Australia, and a general concept of tree decline and dieback. Forest Ecology and Management, v. 215, p. 1--20, 2005. DOI: $10.1016 /$ j.foreco.2005.04.026

KULKARNI, M.; BORSE, T.; CHAPHALKAR, S. Anatomical variability in Grape (Vitis venifera) Genotypes in Relation to Water Use Efficiency (WUE). American Journal of Plant Physiology, v. 2, n. 1, p. 36-43, 2007. DOI: http://dx.doi.org/10.3923/ajpp.2007.36.43

LI, Y.; SPERRY, J. S.; SHAO, M. Hydraulic conductance and vulnerability to cavitation in corn (Zea mays L.) hybrids of differing drought resistance. Environmental and Experimental Botany, Oxford, v. 66, p. 341-346, 2009. DOI: 10.1016/j.envexpbot.2009.02.001

MATTIEllO, E. M.; RUIZ, H. A.; SILVA, I. R. da; BARROS, N. F. de; NEVES, J. C. L.; BEHLING, M. Transporte de boro no solo e sua absorção por eucalipto. Revista Brasileira de Ciência do Solo, Viçosa, v. 33, n. 5, p. 1281-1290, 2009. DOI: http://dx.doi.org/10.1590/S0100-06832009000500021

MORAES, C. B.; FREITAS, T. C. M.; PIERONI, G. B.; ZIMBACK, L.; RESENDE, M. D. V.; MORI, E. S. Estimativas de parâmetros genéticos para seleção precoce de clones de Eucalyptus para região com ocorrência de geadas. Scientia Forestalis, Piracicaba, v. 42, n. 102, p. 219-227, 2014.
PAIVA, A. S.; FERNANDES, E. J.; RODRIGUES, T. J. D.; TURCO, J. E. P. Condutância estomática em folhas de feijoeiro submetido a diferentes regimes de irrigação. Engenharia Agrícola, Jaboticabal, v. 25, p. 161-169, 2005. DOI: http://dx.doi.org/10.1590/S010069162005000100018

PEREIRA, F. J.; CASTRO, E. M. de; SOUZA, T. C. de; MAGALHÃES, P. C. Evolução da anatomia radicular do milho 'Saracura' em ciclos de seleção sucessivos. Pesquisa Agropecuária Brasileira, Brasília, v. 43, n. 12, p. 1649-1656, 2008. DOI: http://dx.doi.org/10.1590/S0100-204X2008001200002

PEREIRA, A. B.; MARQUES JUNIOR, O. G.; RAMALHO, M. A. P.; ALTHOFF, P. Eficiência da seleção precoce em famílias de meios-irmãos de Eucalyptus camaldulensis Dehnh. avaliadas na região noroeste do estado de Minas Gerais. Cerne, Lavras, v. 3, n. 1, p. 67-81, 1997.

PINTO JÚNIOR, J. E.; GARLIPP, R. C. D. Eucalipto. In: ALBUQUERQUE, A. C. S.; SILVA, A. G. (Eds.). Agricultura tropical: Quatro décadas de inovações tecnológicas, institucionais e políticas. Brasília: Embrapa Informações Tecnológica, 2008. p. 801-822.

RIBEIRO, M. N. O.; CARVALHO, S. P. de; PEREIRA, F. J.; CASTRO, E. M. de. Anatomia foliar de mandioca em função do potencial para tolerância à diferentes condições ambientais. Ciência Agronômica, Fortaleza, v. 43, n. 2, p. 354-361, abr./jun. 2012.DOI: DOI: 10.1590/S1806-66902012000200019

SALA, A.; PIPER, F.; HOCH, G. Physiological mechanisms of drought-induced tree mortality are far from being resolved. New Phytologist, v. 186, n. 2, p. 274-281, 2010.

SAS INSTITUTE. Getting started with the SAS learning edition. Cary: SAS Institute, 2002. 200p.

SOUZA, M. J. H.; RIBEIRO, A.; LEITE, H. G.; LEITE, F. P.; MINUZZI, R. B. Disponibilidade hídrica do solo e produtividade do eucalipto em três regiões da Bacia do Rio Doce. Revista Árvore, Viçosa, v. 30, p. 399-410, 2006. DOI: http://dx.doi.org/10.1590/S010067622006000300010

VADEZ, V. Root hydraulics: the forgotten side of roots in drought adaptation. Field Crops Research, Amsterdam, v. 165 , p. $15-24,2014$. 